\title{
SHORT TERM PREDICTION OF WATER LEVEL AND DISCHARGE USING A 2D DYNAMIC WAVE MODEL WITH PARTICLE FILTERS
}

\author{
Yeonsu KIM ${ }^{1}$, Yasuto TACHIKAWA ${ }^{2}$, Sunmin $\mathrm{KIM}^{2}$, \\ Michiharu SHIIBA ${ }^{2}$, Kazuaki YOROZU ${ }^{2}$, Seong Jin $\mathrm{NOH}^{1}$ \\ ${ }^{1}$ Student Member of JSCE, Graduate School of Eng., Civil and Earth Resources Eng., Kyoto Univ. \\ ${ }^{2}$ Member of JSCE, M. Eng., Professor, Dept. of Civil and Earth Resources Eng., Kyoto Univ.
}

\begin{abstract}
A short-term flood prediction algorithm with a 2D dynamic wave model and a particle filter is proposed to consider the uncertainties of hydrologic input data and channel roughness. The particle filter makes it possible to utilize a non-linear and non-Gaussian model for estimating time variant channel roughness and inlet flow uncertainty by considering sequentially updated water stages. The proposed method was applied to the Katsura River located in Kyoto, Japan, and it was verified first through a synthetic experiment. The experiment result shows that the algorithm successfully traces the hidden true values, which are the correct inlet discharges and Manning's roughness coefficient, on a real-time basis. The prediction results were also compared with observed water stages, and they showed good agreements with the observed water stage.
\end{abstract}

Key Words: River discharge, short-term prediction, particle filter, 2D dynamic wave model

\section{INTRODUCTION}

Flood forecasting is crucial information for mitigating and/or protecting the damages induced by flood to our properties and human lives. In general, a hydrological model is utilized to predict the volume and peak time of flood, based on a given rainfall information. Then, a hydraulic model calculates water stage profile for a specific river channel to provide more detailed flood information.

The most successful method of accurate flood forecasting may need precise rainfall information and a well-organized hydrologic model, as well as hydraulic models. However, it is not avoidable to suffer much erroneous forecasting information through a series of conversion, which is from rainfall to discharge and from discharge to water stage. Thus, we are still lacking in our forecasting methods, not only in accurate rainfall forecasting but also in proper hydrologic and hydraulic modeling.

Among many error sources of forecasting in the above mentioned processes, this study focuses on data assimilation into a hydraulic model to properly convert uncertain river discharge information into correct water stage information on a specific river channel. Generally, input data into a hydraulic model, such as inflow from the upper boundary, already include a certain amount of error, and additional system error that comes from a hydraulic model will be added during simulations. To avoid these conventional error sources, this study proposes a new method of hydraulic model utilization, which considers the input error, system error, and observation error using a recursive Monte Carlo simulation algorithm.

Real-time updating of model state variables has already been adopted in many researches with stochastic approaches like the Kalman filter and particle filters. Shiiba et al. ${ }^{1)}$ introduced the Kalman filter into the $1 \mathrm{D}$ dynamic wave model to improve forecasting accuracy considering observed water stage and discharges. Hsu et al. ${ }^{2}{ }^{2}$ showed that updating of the channel roughness coefficient during a simulation considering observed water stage improves prediction capability, and a fixed channel roughness coefficient results in an inaccurate prediction. Discharge also includes uncertainties, as pointed out by Dottori et al. ${ }^{3)}$ and Baldasarre and Montari ${ }^{4)}$ even observed that discharge data include 
Particle filtering system

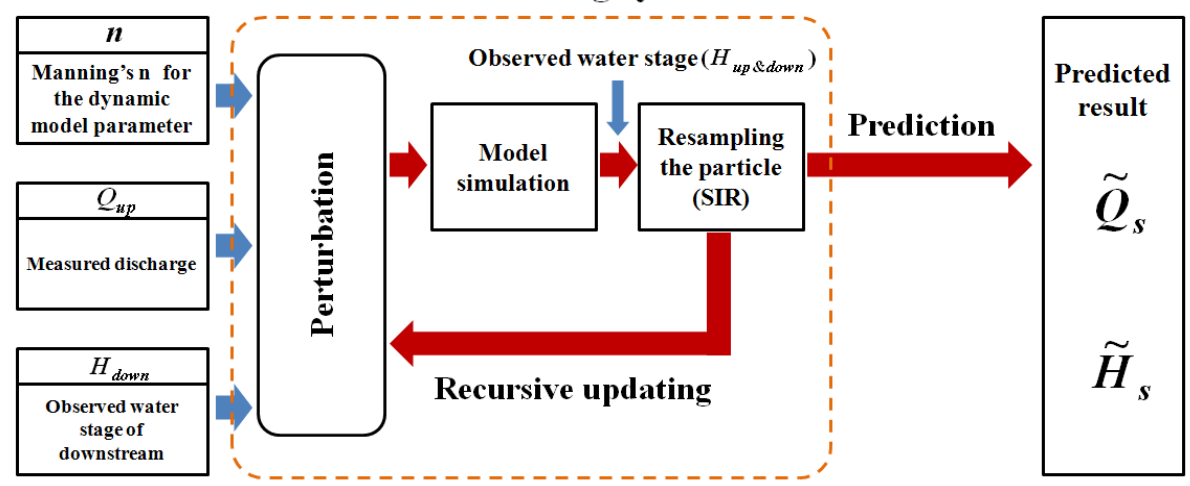

Fig. 1 Real-time water stage prediction algorithm proposed in this study

many uncertainties. In addition, discharge data converted by a rating curve from observed water stages includes many uncertainties.

Arico et $a l^{5)}$ presented a simultaneous estimation method for discharge and channel roughness, and proved that it is essential to consider heterogeneous channel roughness. It is obvious that channel roughness, inlet flow, and the interaction of these factors are critical items for accurate water stage estimation. A stochastic model or a real-time based calibration seems necessary for considering many errors during hydrologic and hydraulic model simulations.

Recent researches have introduced a new type of recursive updating scheme, called particle filters (PFs), into 1D hydraulic models to consider the non-linearity of system models (e.g., Montanari et $a l .{ }^{6}$; Matgen et $a l^{7)}$; Giustarini et $a l^{8)}$ ). Tachikawa et $a l .^{9)}$ also introduced PFs into the 1D hydraulic model, and they improved the predictability of water stages by using the sequentially updated water stages. However, the 1D model was not able to fully consider the geomorphologic characteristics of channel, and the tracking ability of water stage in their study was limited. In terms of the method incorporating noise, the conventional Kalman filter algorithm has limitations in its application to unknown non-normal variances in the state or observational equation (Bradley et al. ${ }^{10)}$ ). However, PFs are applicable in the non-linear system without any Gaussian assumption.

In this study, we introduce an improved prediction algorithm that is based on a $2 \mathrm{D}$ dynamic wave model and particle filters considering input, system, and observation errors. To verify the proposed algorithm, we tested our method on a short reach on the Katsura River in Kyoto, Japan. A 2D dynamic wave model is adopted in this study to reproduce the relation of water stage, discharge, and parameters on a complex river bed more precisely.

The paper is composed of the following sections. Section 2 describes the proposed methodology. Section 3 is devoted to particle filters and noise generation methods. The presented algorithm is verified with a synthetic experiment in section 4. Then, in section 5, we implement the performance analysis of the proposed method. Finally, section 6 summarizes the study.

\section{METHODOLOGY}

\section{(1) Prediction algorithm}

The prediction algorithm largely consists of a particle filtering system (estimation process) and a prediction system (Fig.1). The prediction algorithm runs on results through an estimation process. The estimation process is composed of a perturbation step, an update simulation step, and a resampling step. First, the boundary condition, such as the upstream discharge and the downstream water stage, and model parameter values (channel roughness) are disturbed to consider their uncertainties at the perturbation step. Then, the state variables, which are calculated by the 2D dynamic wave model, and parameter values are sequentially updated in the resampling step according to the weight against the sequentially updated water stage. Next, the state variables and parameter values are transferred to the prediction process to reflect the current state more accurately after updating. The prediction process is calculated up to 6 hours, with the updated state variables and parameter values every hour.

The proposed method is applied to the Katsura River located in Kyoto, Japan. The reach length is about $2 \mathrm{~km}$ and the study reach is covered with 500 structure grids in the calculation domain (Fig. 2). There are two water stage stations at both ends without tributaries, so the characteristics of the reach are good for application of the method since we neglect the lateral flow in consideration of discharge uncertainties. In addition, the flood plain exists on both sides of the main channel. The Kamo River joins at the upstream of the reach and the Uji River joins at the downstream of the reach. 


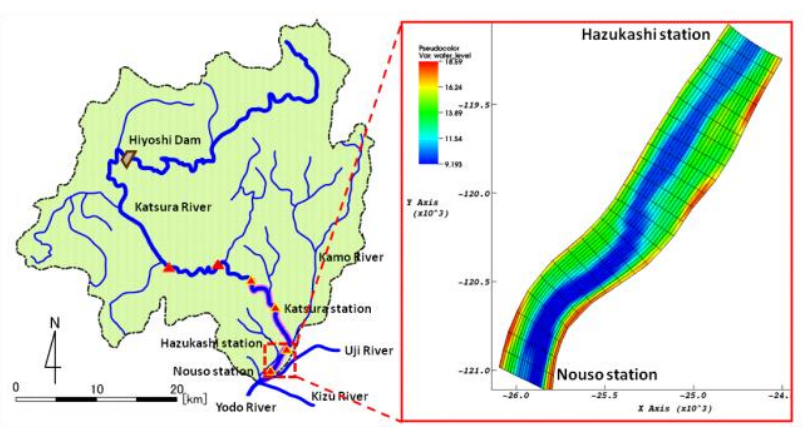

Fig. 2 Location of the study area and the 2D model structure

Although they do not join inside the study reach, the effect of the tributaries and flood plain makes flow conditions very complex.

We will firstly verify our proposed method with a synthetic experiment, which is based on artificial true values. The method is going to be tested on a natural river channel with the observed data to confirm its predictability. The synthetic experiment consists of two steps. The first step is to generate "True Values" with the existing upstream discharge, downstream water level, and arbitrarily generated Manning roughness coefficient. The water stage and discharge of each cross section are simulated through this step, and these simulation results are regarded as "True Values." The second step is to test the particle filter algorithm-namely, whether or not the algorithm successfully traces the hidden "True Values." In this testing step, upstream discharges and downstream water stage, including a certain level of error, are used as the boundary condition. Then some errors were considered in Manning roughness coefficient as well. Based on this condition, the particle filter algorithm with the correct water stage information was utilized to trace the correct discharges and proper Manning roughness coefficient on a real-time basis.

It is believed that a large number of particles improves the accuracy of the estimation and prediction. The algorithm proposed in this study has been tested with different particle numbers, such as 100, 300, and 500 particles. We have determined that 100 particles in our algorithm are sufficient in the sense of calculation time and simulation accuracy.

\section{(2) 2D Dynamic wave model}

The 2D dynamic wave model is composed of the continuity equation (Eq. (1)) and the momentum equation (Eq. (2) and (3)). Then, the equations are numerically solved with Finite Volume Method (FVM) on a structure grid. In dealing with the convection term, the simple first order upwind scheme is utilized. The Adams-Bashforth method is introduced for time integration (Nagata ${ }^{11)}$ ). $\frac{\partial h}{\partial t}+\frac{\partial M}{\partial x}+\frac{\partial N}{\partial y}=0$

$\frac{\partial M}{\partial t}+\frac{\partial u M}{\partial x}+\frac{\partial v M}{\partial y}=-g h \frac{\partial Z_{s}}{\partial x}-\frac{\tau_{b x}}{\rho}+\frac{\partial}{\partial x}\left(-\overline{u^{\prime 2}} h\right)+\frac{\partial}{\partial y}\left(-\overline{u^{\prime} v^{\prime}} h\right)$

$\frac{\partial \mathrm{N}}{\partial \mathrm{t}}+\frac{\partial \mathrm{uN}}{\partial \mathrm{x}}+\frac{\partial \mathrm{vN}}{\partial \mathrm{y}}=-\mathrm{gh} \frac{\partial \mathrm{Z}_{\mathrm{s}}}{\partial \mathrm{y}}-\frac{\tau_{\mathrm{by}}}{\rho}+\frac{\partial}{\partial \mathrm{x}}\left(-\overline{\mathrm{u}^{\prime} \mathrm{v}^{\prime}} \mathrm{h}\right)+\frac{\partial}{\partial \mathrm{y}}\left(-\overline{\mathrm{v}^{\prime 2}} \mathrm{~h}\right)$

where $h$ is water depth and $Z_{s}$ is water stage; $t$ is time; $u$ and $v$ are depth averaged velocity in $\mathrm{x}$ and y direction; $M$ and $N$ denote discharge flux in $\mathrm{x}$ and $\mathrm{y}$ direction; $\rho$ is density of water; and $\tau_{b x}$ and $\tau_{b y}$ are the bed shear stress in $\mathrm{x}$ and $\mathrm{y}$ direction.

\section{PARTICLE FILTERING SYSTEM}

PFs perform the sequential Monte Carlo (SMC) estimation based on particle representations of probability densities within Bayesian theorem (Ristic et al. ${ }^{12)}$ ). The sequential process of particles in time using the nonlinear model is preceded up to the next available measurement (Salmon and Feyen ${ }^{13)}$ ). Among the various PFs, the sequential importance resampling (SIR) method is introduced in this study since the SIR can reduce the meaningless calculations and estimate current state more exactly.

\section{(1) Perturbation process}

From the assumption that all errors come from uncertainties of channel roughness and inlet inflow, we incorporate some errors to Manning's roughness coefficient, inlet discharge, and downstream water stage before the simulation step.

The general method, which adds white noise to the chosen particles like Eq. (6), shows the limitations in tracking rapidly changing parameter values and state variables. Therefore, the modified extrapolation method, which showed appropriate ability when tracking abruptly changed channel roughness with Kalman filter in the study of Crissman et al. ${ }^{14)}$, is introduced to generate the noise of Manning roughness coefficient and inlet flow, as in Eq. (5) and Eq. (4), respectively.

The polynomial extrapolation method reduces the variation of particles, but it shows the weakness in inflection point, such as peak time of discharge hydrograph. As an alternative to these problems, we introduced the two types of perturbation equations to generate noise of Manning's roughness coefficient. In order to choose the perturbation equation, the discharge ratio $\left(\left(Q_{t}^{o b s}-Q_{t-1}^{o b s}\right) / Q_{t}^{o b s}\right)$, where $Q_{t}^{o b s}$ is the discharge at the current time and $Q_{t-1}^{o b s}$ is the discharge at the previous time, is 
introduced. Several cases were tested to determine the criteria to choose the perturbation equation, and it has been confirmed that a $20 \%$ discharge ratio is the proper value in our subject river channel. In the case when the ratio is less than $20 \%$, Eq. (5) is applied, and Eq. (6) is applied when the ratio is more than $20 \%$. It should be noted that this value is not a general index for other river channels.

$$
\begin{array}{rlrl}
Q_{t+1}^{i} & =Q_{t}^{i}+\left(Q_{t+1}^{o b s}-Q_{t}^{o b s}\right)+\varepsilon_{t+1}^{i} & \varepsilon_{t+1}^{i} & \sim N\left(0,0.1 Q_{t+1}^{o b s}\right) \\
n_{t+1}^{i} & =n_{t}^{i}+(4) \\
n_{t+1}^{i} & \left.=n_{t}^{i}+\hat{n}_{t+1}^{i}\right)+\eta_{t+1}^{i} & \eta_{t+1}^{i} \sim N(0,0.005) & (5) \\
h_{t+1}^{i} & =h_{t}^{o b s}+\alpha_{t+1}^{i} & \omega_{t+1}^{i} \sim N(0,0.01) & (6) \\
& & \alpha_{t+1}^{i} \sim N(0,0.1) & (7)
\end{array}
$$

where $Q_{t}^{i}, \quad n_{t}^{i}$ and $h_{t}^{i}$ indicate the discharge, Manning roughness $\mathrm{n}$, and downstream water stage of $i$-th particle at time $t$, respectively. $\varepsilon_{t}^{i}, \eta_{t}^{i}, \omega_{t}^{i}$ and $\alpha_{t}^{i}$ indicate the errors drawn from the normal distribution. $Q_{t}^{\text {obs }}$ and $h_{t}^{\text {obs }}$ indicate the observed discharge and the observed downstream water stage. $\hat{n}_{t}$ indicates the average roughness coefficient in each time step according to the weight in Eq. (11).

\section{(2) Resampling process}

The key idea in the particle filters is to represent the posterior pdf $p\left(x_{t} \mid y_{t}\right)$ with a set of random draws, called particles (Salmon and Feyen ${ }^{13)}$ ). The posterior density at time $t$ is approximated as Eq. (8) and the updated equation can be shown as Eq. (9).

$$
\begin{aligned}
& p\left(x_{t} \mid Y_{t}\right) \approx \sum_{i=1}^{N} w_{t}^{i} \delta\left(x_{t}-x_{t}^{i}\right) \\
& w_{t}^{i} \propto w_{t-1}^{i} \frac{p\left(z_{t} \mid x_{t}^{i}\right) p\left(x_{t}^{i} \mid x_{t-1}^{i}\right)}{q\left(x_{t}^{i} \mid x_{t-1}^{i}, y_{t}\right)}
\end{aligned}
$$

where $x_{t}^{i}, w_{t}^{i}$ denote $i$ th particle and its weight, respectively. $\delta$ indicates the Direc delta function and $x_{t}, y_{t}$ are the state vector and the measurement vector at time $t$.

At each updating step, the weight, which is calculated by Eq. (9), is calculated against the observed water stage of 2 points (upstream and downstream ends), respectively. Then, we calculated joint probability by multiplying the likelihood of 2 points to represent the weight of each particle (Eq. (10)) (Matgen et al. ${ }^{7)}$ ). The joint probability of each particle was normalized as follows (Eq. (11)):

$$
w_{t}^{i}=\prod_{j=1}^{N_{p}} w_{t}^{i, j}
$$

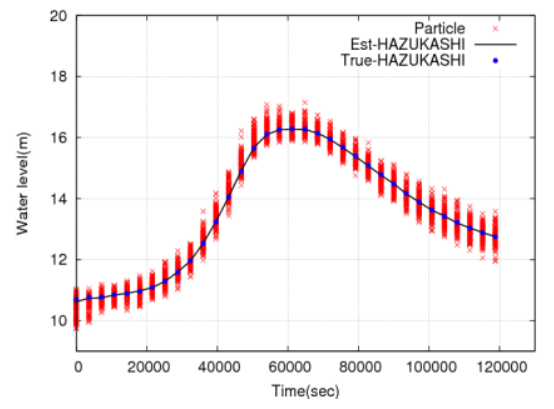

Fig. 3 The comparison of averaged water stage in the synthetic experiment

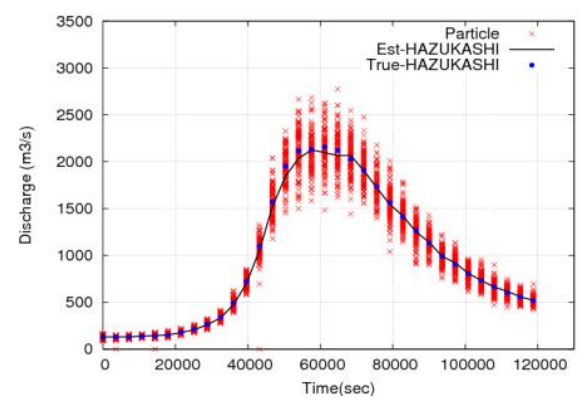

Fig. 4 The comparison of inlet discharge in the synthetic experiment

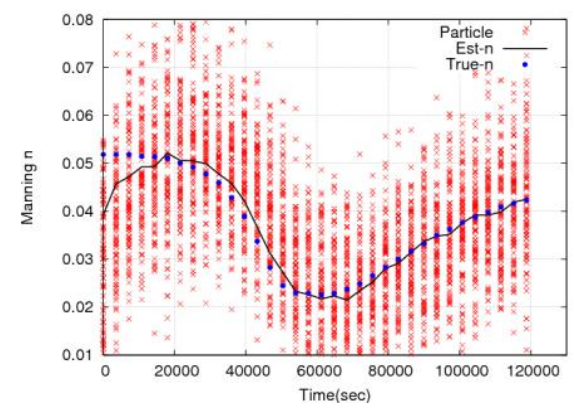

Fig. 5 The comparison of Manning roughness coefficient in the synthetic experiment

$W_{t}^{i}=\frac{w_{t}^{i}}{\sum_{j=1}^{N} w_{t}^{i}}$

where $w_{t}^{i, j}$ indicates the weight of $i$ th particle at time $t$ calculated against $j$ th observation. $w_{t}^{i}$ denotes the normalized weight of each particle at time $t, N_{p}$ is the number of updating points.

According to the normalized weight, the particles are removed or multiplied in the resampling step. The systematic resampling method presented in Kitagawa ${ }^{15}$ is introduced among various resampling methods.

\section{(3) Constraints on noise generation}

This method considers various cases with the disturbed channel roughness and inlet discharge, but particles are controlled by only the normalized 
weight calculated against the updated water stage. Therefore, it is not enough to control the two randomly generated variables - the Manning roughness and inlet discharge - with only the weight calculated against updated water stage. In order to reduce the meaningless calculation, we assume the errors of observed discharge are fewer than $35 \%$.

\section{EVALUATION WITHSYNTHETIC DATA}

\section{(1) Synthetic experimental design}

We verify the estimation method with the synthetic data. The synthetic data is based on the real event, which occurs from 6:00 on October 20, 2004 , to $15: 00$ on October 21, 2004, at the natural river reach from Hazukashi station to Nosou station (See Fig. 2). In general, Manning's roughness is dependent on water depth and ranges from 0.02 to 0.07. Thus, we present a simple relationship equation of Manning's roughness to verify the proposed algorithm. The equation is based on the assumption that Manning's roughness coefficient $\left(n_{t}\right)$ is linearly inverse proportional to water stage $\left(h_{t}\right)$ at time $t$ as follows:

$n_{t}=\left(18-h_{t}\right) / 250+0.02$

The water stage of upstream is generated from the first step of the synthetic experiment. It is considered to be the synthetic truth instead of the measured upstream water stage. Then predetermined synthetic truths, which are water stage, input discharge, and Manning $\mathrm{n}$, are utilized as verification data and marked as "TRUE" in the Figs. $\mathbf{3}, \mathbf{4}$, and 5. In addition, only the water stage of synthetic truth is utilized as updating data for the second step of the synthetic experiment.

\section{(2) Evaluation results}

Averaged values of water stage, inlet discharge, and Manning's roughness coefficient are marked as a black line. The values of each particle are marked as red points in Figs. 3, 4, and 5. According to the graphs, the averaged values are similar to "True," which is synthetic truth in each graph. Root mean square error (RMSE) is utilized to compare the averaged values with synthetic truth. The RMSE for water stage and discharge are $0.11 \mathrm{~m}$ and $31.75 \mathrm{~m}^{3} / \mathrm{s}$, respectively. Then, the range of particles covers the "True."

Particularly, the initial errors of Manning's roughness were also corrected during the tracking procedure by the learning process of particle filters. Such a simultaneous estimation of the Manning's n and inlet discharge could present approximately averaged values and reduce the errors.

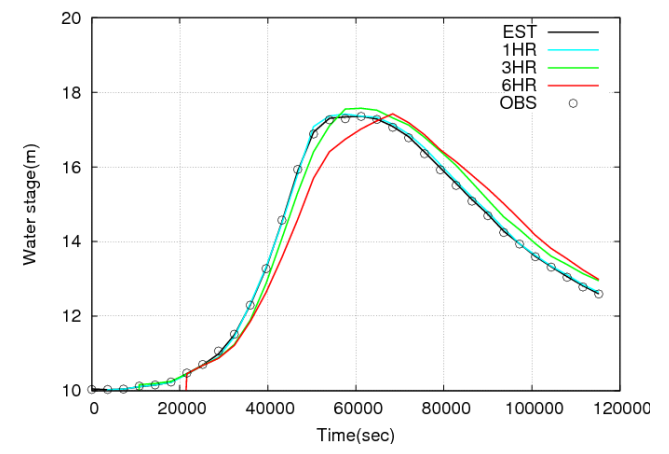

Fig. 6 The comparison of prediction water stage at Hazukashi

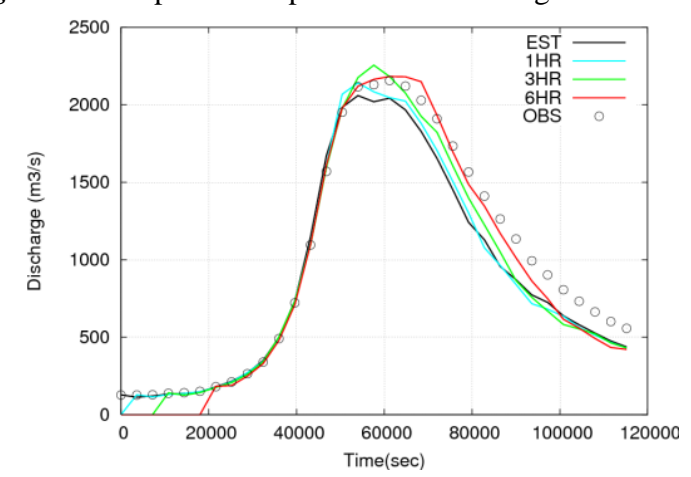

Fig. 7 The comparison of prediction discharge at Hazukashi

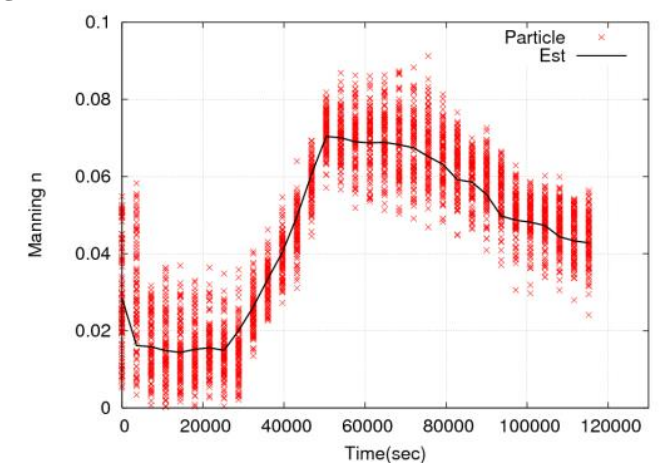

Fig. 8 The estimated tendency of Manning roughness

Table 1 Water stage comparison of the estimation and prediction at Hazukashi

\begin{tabular}{ccc}
\hline Classification & $\begin{array}{c}\text { RMSE of water stage } \\
(\mathrm{m})\end{array}$ & $\begin{array}{c}\text { Maximum absolute } \\
\text { error }(\mathrm{m})\end{array}$ \\
\hline \hline Estimation & 0.024 & 0.075 \\
\hline 1hr prediction & 0.097 & 0.258 \\
\hline 3hr prediction & 0.291 & 0.758 \\
\hline 6hr prediction & 0.565 & 1.376 \\
\hline
\end{tabular}

\section{PREDICTION RESULTS AND ANALYSIS USING OBSERVED DATA}

In this section, the predictability of the algorithm with observed data is presented. Most of the applied conditions for this simulation are the same with synthetic experiment, but the simulation is different in that this test utilizes real observed water stage for updating and true values do not exist.

In the prediction process, Manning's roughness coefficient is fixed as the value chosen in the resampling step at the current time step, and the 
predicted inlet flows up to 6 hours are determined by the proportions of particle's inlet discharge against the given discharge at the current time step.

The prediction process performs up to 6 hours. Then the results at 1 hour (1HR), 3 hours (3HR), and 6 hours $(6 \mathrm{HR})$ are compared with the observed water stage and discharge (OBS) at Hazukashi station (Figs. 6 and 7). EST indicates the average values with the weight, while the prediction results are averaged with even weight. Table 1 shows the comparison results of the estimation and prediction of the water stage.

The estimated water stage and 1 hour ahead water stage shows good agreement with the observed one. With increased lead time, the accuracy of the prediction result is less than the 1 hour ahead prediction result due to the fixed roughness coefficient chosen in the resampling step, while the real channel roughness varies according to time.

In addition, the estimated Manning's roughness coefficient is plotted in Fig. 8 with the values of each particle. Manning's roughness coefficient is so varied due to the flood plain and backwater increasing the channel roughness when flooding occurs. Finally, Fig. 7 also shows that the estimated discharges are similar to the observed discharges, even though there is some discrepancy at the peak point and the recession limb of the hydrograph. However, the discrepancy in Fig. 7 may come from the rating curve conversion because the discharge is converted from the observed water stage.

\section{CONCLUSION}

Stochastic approaches are introduced to the 2D dynamic wave model to incorporate errors to consider the uncertainties of inlet discharge and channel roughness. The estimation method is verified with the synthetic experiment, and prediction results were compared with the observed water stage. The results of tests implemented in this study show that the proposed algorithm is not only an efficient prediction tool for water stage, but also a simultaneous estimation tool of inlet discharge and channel roughness.

In further research, the lateral flow will be considered and the method will be applied to more events and other reaches for more general approach to natural channels.

\section{REFERENCES}

1) Shiiba, M., Laurenson, X., and Tachkawa, Y.: Real-time stage and discharge estimation by a stochastic-dynamic flood routing model, Hydrological Process, Vol.14, pp.481-495, 2000.
2) Hsu, M.H., Fu, J.C., and Liu, W.C.: Dynamic routing model with real time roughness updating for flood forecasting, Journal of Hydraulic Engineering, Vol.132, pp.605-619, 2006.

3) Dottori, F., Martina, M. L. V., and Todini, E.: A dynamic rating curve approach to indirect discharge measurement, Hydrol. Earth Syst. Sci., Vol.13, pp.847-863, 2009.

4) Di Baldassarre, G. and Montanari, A.: Uncertainty in river discharge observations: a quantitative analysis, Hydrol. Earth Syst. Sci., Vol.13, pp.913-921, 2009.

5) Aricò, C., Nasello, C., and Tucciarelli, T.: Using unsteady-state water level data to estimate channel roughness and discharge hydrograph. Adv. Wat. Res., Vol.32, pp.1223-1240, 2009.

6) Montanari, M., Hostache, R., Matgen, P., Schumann, G., Pfister, L., and Hoffmann, L.: Calibration and sequential updating of a coupled hydrologic model using remote sensing-derived water stage, Hydrol. Earth Syst. Sci., Vol.13, pp.367-380, 2009.

7) Matgen, P., Montanari, M., Hostache, R., Pfister, L., Hoffmann, L., Plaza, D., Pauwels, V.R.N., De Lannoy, G.J.M., De Keyser, R., and Savenije, H.H.G.: Towards the sequential assimilation of SAR-derived water stages into hydraulic models using the particle filter: proof of concept, Hydrol. Earth Syst. Sci., Vol.14, pp.1773-1785, 2010.

8) Giustarini, L., Matgen, P., Hostache, R., Montanari, M., Plaza, D., Pauwels, V.R.N., de Lannoy, G.J.M., de Keyser, R., Pfister, L., Hoffmann, L., and Savenije, H.H.G.: Assimilating SAR-derived water level data into a hydraulic model: a case study, Hydrol. Earth Syst. Sci., Vol.15, pp.2349-2365, 2011.

9) Tachikawa, Y., Sudo, J., Shiiba, M., Yorouzu, K., and Kim, S.: Development of a real-time rivers stage forecasting method using particle filter, Annual Journal of Hydraulic Engineering, JSCE, Vol.55, pp. S_511-S_516, 2011.

10) Bradely, P. C., Nicholas, G., Polson, N.G., and David, S.S.: A Monte Carlo Approach to Nonnormal and Nonlinear State-Space Modeling, Journal of the American Statistical Association, Vol.87, pp.493-500, 1992.

11) Nagata, T.: Hydraulics formulae: Hydraulics worked examples with CD-ROM, Hydraulic committee, JSCE, pp.16-19, 2002.

12) Ristic, B., Arulampalam, S., and Gordon, N.: Beyond the Kalman Filter, Artech House, pp. 35-65, 2004.

13) Salamon, P. and Feyen L.: Disentangling uncertainties in distributed hydrological modelling using multiplicative error models and sequential data assimilation, Water Resour. Res., Vol.46, 2010.

14) Crissman, R.D., Chiu, C-L., Yu, W., Mizumura, K., and Corbu, I.: Uncertainties in Flow Modeling and Forecasting for Niagara River, American Society of Civil Engineers Journal of Hydraulic Engineering, ASCE, Vol.119, pp.1231-1250, 1994.

15) Kitagawa, G.: Non-Gaussian State-Space Modeling of Nonstationary Time Series, Journal of the American Statistical Association, Vol.82, pp.1032-1063, 1996.

(Received September 30, 2011) 